


\section{MCP}

Editor-in-Chief

Frederic R. Curtiss, PhD, RPh, CEBS

830.935.4319, fcurtiss@amcp.org

\section{Associate Editor}

Kathleen A. Fairman, MA

602.867.1343, kfairman@amcp.org

\section{Peer Review Administrator}

Jennifer A. Booker, 703.317.0725

jmcpreview@amcp.org

\section{Graphic Designer}

Margie Hunter, 703.297.9319

mhunter@amcp.org

\section{February Supplement Editor}

Joshua J. Spooner, PharmD, MS

reviewmax@yahoo.com

\section{Account Manager}

Peter Palmer, 800.486.5454, ext. 13

peter@promedgroup.net

\section{Publisher}

Judith A. Cahill, CEBS

Executive Director

Academy of Managed Care Pharmacy

This supplement to the Journal of Managed Care Pharmacy (ISSN 1083-4087) is a publication of the Academy of Managed Care Pharmacy, 100 North Pitt St., Suite 400, Alexandria, VA 22314; 703.683.8416; 703.683.8417 (fax).

Copyright $\odot 2009$, Academy of Managed Care Pharmacy. All rights reserved. No part of this publication may be reproduced or transmitted in any form or by any means, electronic or mechanical, without written permission from the Academy of Managed Care Pharmacy.

POSTMASTER: Send address changes to JMCP,

100 North Pitt St., Suite 400, Alexandria, VA 22314.

\section{Supplement Policy Statement}

\section{Standards for Supplements to the}

Journal of Managed Care Pharmacy

Supplements to the Journal of Managed Care Pharmacy are intended to support medical education and research in areas of clinical practice, health care quality improvement, or efficient administration and delivery of health benefits. The following standards are applied to all JMCP supplements to ensure quality and assist readers in evaluating potential bias and determining alternate explanations for findings and results.

1. Disclose the principal sources of funding in a manner that permits easy recognition by the reader

2. Disclose the existence of all potential conflicts of interest among supplement contributors, including financial or personal bias.

3. Describe all drugs by generic name unless the use of the brand name is necessary to reduce the opportunity for confusion among readers.

4. Identify any off-label (unapproved) use by drug name and specific off-label indication.

5. Strive to report subjects of current interest to managed care pharmacists and other managed care professionals.

6. Seek and publish content that does not duplicate content in the Journal of Managed Care Pharmacy.

7. Subject all supplements to expert peer review.

Melody Ryan, PharmD, MPH, GCP, BCPS, is Associate Professor in the College of Pharmacy, Division of Pharmacy Practice and Science and in the College of Medicine, Department of Neurology at the University of Kentucky Chandler Medical Center in Lexington. Her practice site is at the Neurology Ambulatory Care Clinic of the Lexington Veteran Affairs Medical Center in Lexington, Kentucky. She earned her doctor of pharmacy degree and masters degree in public health from the University of Kentucky. She completed a pharmacy practice residency at Duke University and a neuroscience fellowship at the University of Kentucky. Ryan currently serves as Chair-Elect for the Academy of Pharmaceutical Research and Science Clinical Sciences section of the American Pharmaceutical Association.

Sara Deno, PharmD, is Clinical Services Manager for BioScrip, Inc., in Eden Prairie, Minnesota, where she supports clinical initiatives across all business units for the pharmaceutical company. In this position, Deno is well-versed in the use of biologics in the treatment of immune diseases such as multiple sclerosis as well as in the areas of oncology and virology. Deno has served as a Pharmacy Manager for Walgreens, Toxicologist at Prosar, and Pharmacist-in-Charge at BioScrip, Inc., prior to assuming her current position in January 2007. Her areas of interest include designing adherence and persistency programs in partnership with pharmaceutical companies and payers, with a concentration on adherence and persistency through medication management protocols. She earned her doctor of pharmacy degree from the University of Minnesota in 2003.

Howard L. Zwibel, MD, is Medical Director of the Multiple Sclerosis Center at Doctors Hospital in Coral Gables, Florida. He earned his medical degree from Hahnemann Medical College in Philadelphia, Pennsylvania, and completed a residency in neurology at Jackson Memorial Hospital at the University of Miami. Zwibel currently serves as a member of the Clinic and Practice Committee of the National Multiple Sclerosis Society and has previously served as Chairman of the Practice Committee of the Multiple Sclerosis Section of the American Academy of Neurology. He is a member of the Board of Governors of the Consortium of Multiple Sclerosis Centers and is a voluntary Professor of Neurology at the University of Miami, Miller School of Medicine. He is a Diplomat of the American Board of Neurology.

\section{Faculty Disclosures}

All 3 authors received compensation as speakers in the symposium held on October 15, 2008. Melody Ryan and Sara Deno disclose no financial interest and or other potential conflict of interest relating to the subject matter contained within this supplement. Howard L. Zwibel discloses that he is a consultant to Teva Neuroscience and Bayer. Zwibel is also a member of the Speaker's Bureau for Teva Neuroscience.

\section{Off-Label Use}

There is no mention of off-label use of the drugs described in this educational activity.

\section{Acknowledgements}

The authors acknowledge Betsy R. Sanchez, BS, Chris R. Prostko, PhD, and Frank L. Urbano, MD, FACP, from PRIME ${ }^{\circledR}$ (Tamarac, Florida) for their assistance with the development and revision of this supplement. 


\section{Table of Contents}

\section{Review of the Clinical Debate Regarding Interventions for Multiple Sclerosis}

Melody Ryan, PharmD, MPH, GCP, BCPS; Sara Deno, PharmD; and Howard L. Zwibel, MD

S2 Overview of Multiple Sclerosis

S4 Debate \#1: When and How Should Treatment be Initiated in the Newly Diagnosed Patient with Multiple Sclerosis?

S8 Debate \#2: How Can Medication Adherence be Improved in Multiple Sclerosis?

S10 Debate \#3: What Factors Should be Considered in the Patient Receiving Long-Term Therapy for Multiple Sclerosis?

S13 Conclusions

S16 Continuing Education

CE/CME Submission Instructions and Posttest Worksheet

\footnotetext{
Target Audience

This activity is intended for managed care pharmacists and managed care physicians. This is an application-based learning activity.
Learning Objectives
Upon completion of this program, participants will be able to:
1. Apply current evidence to address the therapeutic ambiguities in multiple sclerosis management.
2. Define strategies to improve adherence to disease-modifying therapies for multiple sclerosis.
3. Analyze newer methods to ascertain therapeutic effectiveness in patients with multiple sclerosis.

\section{Funding and Original Presentation of This Learning Activity}

This supplement was sponsored by PRIME ${ }^{\circledR}$ through an independent educational grant from Teva Neuroscience. Articles in this JMCP supplement are based on the proceedings of a satellite symposium held October 15, 2008, at the Kansas City Convention Center in Kansas City, Missouri, in conjunction with the Academy of Managed Care Pharmacy's 2008 Educational Conference, which was supported by an independent grant from Teva Neuroscience.

Release date: February 1, 2009

Expiration date: February 1, 2011

\section{Continuing Education Credit}

Participants who attended the satellite symposium, "Resolving the Clinical Debate Regarding Interventions in Multiple Sclerosis," at the AMCP annual meeting and who obtained continuing education credit for that learning activity held on October 15, 2008 are not eligible for continuing education credit for this supplement.

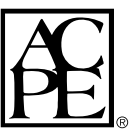

\section{Pharmacists}

Professional Resources in Management Education, Inc. (PRIME ${ }^{\circledR}$ ) is accredited by the Accreditation Council for Pharmacy Education (ACPE) as a provider of continuing pharmaceutical education. A total of 0.150 CEUs (1.5

contact hours) will be awarded and a continuing education statement will be sent to pharmacists for successful completion of this continuing education program, which is defined as receiving a minimum score of $70 \%$ on the post test and completion of the Program Evaluation form. ACPE Universal Program Number. 255-000-08-028-H01-P.

\section{Physicians}

Professional Resources in Management Education, Inc. (PRIME ${ }^{\circledR}$ ) is accredited by the Accreditation Council for Continuing Medical Education (ACCME) to provide continuing medical education for physicians. This activity has been planned and implemented in accordance with the Essential Areas and Policies of ACCME through sponsorship of PRIME $^{\circledR}$. PRIME $^{\circledR}$ designates this educational activity for a maximum of 1.5 category 1 credits toward the AMA Physician's Recognition Award. Each physician should claim only those hours of credit that he/she actually spent on the activity. 


\title{
Review of the Clinical Debate Regarding Interventions for Multiple Sclerosis
}

\author{
Melody Ryan, PharmD, MPH, GCP, BCPS; Sara Deno, PharmD; and Howard L. Zwibel, MD
}

\begin{abstract}
BACKGROUND: Multiple sclerosis (MS) is a debilitating and progressive neurologic disorder characterized by relapses and neurological deterioration. The mainstay of treatment for MS are the disease-modifying therapies (DMTs), which are costly biologic agents designed to reduce the rate of relapse and progression of the disease. Despite the presence of several approved medications and a substantial amount of experience with these agents, various uncertainties remain regarding the optimal management of MS. Issues that are frequently debated include when to start therapy, which agent to use, how to improve adherence to DMT, and issues related to long-term use of DMTs.

OBJECTIVE: To familiarize managed health care professionals with current issues and ongoing challenges in the management of MS, and to consider potential strategies to overcome these challenges and optimize treatment outcomes.

SUMMARY: Despite the existence of effective therapies for MS, clinical debate exists regarding the optimal management of patients with this disease. While there are few clear answers to the questions posed by current issues in MS management, with careful consideration and investigation of existing medical evidence, the best course of action for the patient with MS can be estimated and hopefully refined in years to come.
\end{abstract}

J Manag Care Pharm. 2009;15(1)(Suppl S-b):S1-S17

Copyrighto 2009, Academy of Managed Care Pharmacy. All rights reserved.

\section{Authors}

MELODY RYAN, PharmD, MPH, GCP, BCPS, is Associate Professor, Department of Pharmacy Practice and Science and Department of Neurology, University of Kentucky Chandler Medical Center, Lexington, Kentucky.

AUTHOR CORRESPONDENCE: Melody Ryan, PharmD, MPH, Associate Professor, University of Kentucky Chandler Medical Center, 800 Rose Street, Room C117, Lexington, KY 40536-0293. Tel: 859.257.8790; Fax: 859.323.0069; E-mail: maryan1@pop.uky.edu

SARA DENO, PharmD, is Clinical Services Manager, BioScrip, Eden Prairie, Minnesota.

AUTHOR CORRESPONDENCE: Sara Deno, PharmD, Clinical Services Manager, BioScrip, Inc., 10050 Crosstown Circle, Suite 300, Eden Prairie, Minnesota, 55344. Tel: 952.979.3690; Fax: 952.352.6663; E-mail: sdeno@bioscrip.com

HOWARD L. ZWIBEL, MD, is Medical Director, The Multiple Sclerosis Center at Doctors Hospital, Coral Gables, Florida.

AUTHOR CORRESPONDENCE: Howard Zwibel, MD, Medical Director, The Multiple Sclerosis Center at Doctors Hospital, 6862 Granada Boulevard, Coral Gables, Florida 33146. Tel: 305.665.2344; Fax: 305.662.8775; E-mail:zwibelmdms@aol.com

\section{Overview of Multiple Sclerosis}

Multiple sclerosis (MS) is a chronic disease of the central nervous system (CNS) characterized by inflammation, demyelination, and axonal degeneration. ${ }^{1,2}$ MS is the most common cause of neurologic disability in young adults, with a peak age of onset between 20 and 40 years. ${ }^{3,4}$ MS is most prevalent among Caucasians, with the worldwide prevalence estimated to be 2.5 million cases. ${ }^{5}$ Approximately 10,000 newly diagnosed cases of MS are reported annually, with at least a 2:1 female to male ratio. ${ }^{3}$

MS is believed to be an immune-mediated disorder and has been observed to have a genetic susceptibility in some patients. ${ }^{6}$ Although the etiology of MS is not completely understood, environmental and viral factors are thought to play a role in its development. ${ }^{7}$ Human herpes virus 6 (HHV-6) infection has been implicated as a potential etiologic factor in MS, but other infectious agents are also thought to be involved in the pathology of MS., ${ }^{7,8}$

MS possesses both inflammatory and neurodegenerative components. The inflammatory nature of MS is related to the acute relapses that are observed in MS patients, since when inflammation decreases, the symptoms of MS also abate. ${ }^{3}$ However, it is also believed that axons become damaged in MS and that this is associated with permanent neurologic dysfunction. ${ }^{1}$ The neurodegenerative aspect of MS is a relatively new concept and is thought to be related to the progressive disability observed in MS patients over time.

MS lesions can occur in any area of the brain, but areas most frequently affected include the optic nerve, the periventricular white matter, cerebral cortex, brainstem, cerebellum, and the spinal cord. Patients with MS typically experience symptoms related to the location of the corresponding CNS lesions.

The differential diagnosis of MS is broad and includes infectious disorders such as Lyme disease, neurosyphilis, progressive multifocal leukoencephalopathy (PML), human immunodeficiency virus (HIV), and the human T cell leukemia virus-1 (HTLV-1); inflammatory conditions such as systemic lupus erythematosus (SLE), Sjögren's syndrome, sarcoidosis, Behçet's disease, and other CNS vasculitides; metabolic conditions such as vitamin B12 deficiency; and other neurologic disorders including cerebral autosomal dominant arteriopathy with subcortical infarcts and leukoencephalopathy (CADASIL), CNS lymphoma, cervical spondylosis, motor neuron disease, myasthenia gravis, or neoplasms. ${ }^{9-11}$

\section{Classification of MS and Associated Disability}

Presently, there are 4 recognized types of MS. Relapsingremitting MS (RRMS) is characterized by unpredictable attacks that occur followed by periods of remission, wherein 
damage may resolve or remain permanent. Approximately 85\% of patients initially diagnosed with MS have the RRMS form of the disease. ${ }^{12,13}$ The majority of RRMS patients will eventually develop Secondary Progressive MS (SPMS), which is characterized by an initial period of attacks and remissions and then a sudden steady decline of CNS function without periods of remission. Those patients with MS who are not classified as having RRMS are said to have either Primary Progressive MS (PPMS) or Progressive-Relapsing MS (PRMS). PPMS, which is the initial diagnosis in only about $10 \%$ of individuals, is characterized by a steady decline from the onset, without remissions and without clear attacks. ${ }^{13}$ PRMS is characterized by a steady decline in CNS function from the onset of MS, but with clearly identifiable attacks. According to the National Multiple Sclerosis Society, only about $5 \%$ of people with MS have PRMS. ${ }^{13}$

Natural history studies have been helpful in characterizing the progression and outcomes of patients with MS. Of those that present with RRMS, 58\% of patients will progress to SPMS after having the disease for 11 to 15 years. ${ }^{12}$ Moreover, the percentage of patients with PPMS at onset increases with each decade of life; the majority of patients older than 50 years of age at diagnosis have PPMS. ${ }^{14}$ Natural history studies have also shown that mortality from MS is low (life expectancy is at least 25 years after diagnosis and most patients die of unrelated conditions); the average number of relapses is 1 per year, decreasing over time; and $25 \%$ of patients never lose the ability to perform daily activities. ${ }^{12}$ Additionally, approximately $15 \%$ of patients become severely disabled within a short time; the median time to require assistance with walking is 15 years and to become bedbound is 46 years. ${ }^{12}$

MS relapses, which are also referred to as exacerbations, attacks, flare-ups, or acute episodes, are focal disturbances of function that last more than 24 hours. ${ }^{15}$ Relapses are a hallmark of MS and are defined clinically as the acute or subacute onset of neurologic dysfunction that reaches a peak, followed by remission during which the symptoms and signs of MS resolve to a variable extent. Relapses may occur in the absence of environmental, metabolic, or infectious processes and generally evolve over a few days, reaching a plateau before resolving to a variable degree over weeks or months. ${ }^{16}$ The minimum duration of a relapse arbitrarily is set at 24 hours, and a relapse can consist of any neurologic symptom associated with the initial diagnosis of MS. Fever, physical activity, metabolic activity, or stress have all been shown to trigger a relapse. The frequency of relapses varies depending upon the population, although the majority of patients average less than 1 relapse a year (approximately 0.4 to 0.6 relapses/year). ${ }^{14}$ The onset of relapses affects a patient's longterm disability, meaning that the more frequently relapses occur early in the course of multiple sclerosis, the greater a patient's long-term disability will be.

The Expanded Disability Scale Score (EDSS) is a method used to quantify disability in patients with MS, as well as to monitor changes in the level of disability over time. Developed by

\section{FIGURE 1 Assessing Disability Progression: The EDSS}

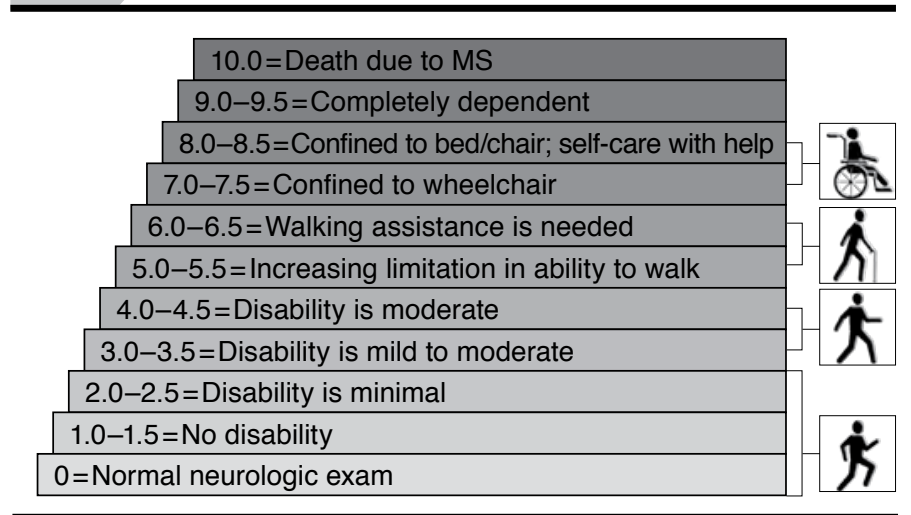

Kurtzke JF. Neurology. 1983;33:1444-52.17

EDSS = Expanded Disability Status Scale.

Kurtzke, ${ }^{17}$ the EDSS quantifies disability in 8 Functional Systems (FS) and allows neurologists to assign a Functional System Score (FSS) in each of these. The FS consists of: (1) pyramidal (weakness or difficulty moving limbs); (2) cerebellar (ataxia, loss of coordination, or tremors); (3) brainstem (speech and swallowing difficulty); (4) sensory (numbness or loss of sensation); (5) bowel and bladder function; (6) visual function; (7) cerebral (or mental) functions; and (8) other. EDSS scores of 1.0 to 4.5 refer to patients with MS who are fully ambulatory, while scores of 5.0 to 9.5 are defined by the progressive impairment of ambulation (Figure 1). An EDSS score of 10 is equivalent to death due to MS. ${ }^{17}$ Although it is the standard for evaluating disability in MS, the EDSS has been criticized for putting great emphasis on mobility and deemphasizing other symptoms of the disorder. ${ }^{18}$

\section{Diagnosis of Multiple Sclerosis}

MS is diagnosed through a variety of means. Lumbar puncture is often used to confirm the diagnosis when compatible symptoms exist. The myelin basic protein level may be elevated during acute exacerbations of MS, but oligoclonal bands are a better potential indicator of the presence of MS. Oligoclonal bands (OCBs) are present in $85 \%$ to $95 \%$ of patients with MS, and the presence of OCBs in symptomatic patients is highly predictive of progression to MS. ${ }^{19}$ Qualitative assessment of OCBs in cerebral spinal fluid (CSF) is recommended for diagnosis of MS; if initial results are equivocal, a repeat lumbar puncture may be necessary.

Visual evoked potentials (VEP) may also be used to support a diagnosis of MS. Evoked potentials are electrical events generated by peripheral stimulation of a sensory organ, such as the eye or ear, and are used to detect abnormal CNS function that may be otherwise undetectable. Detection of a subclinical lesion by VEP in a site remote from the region of clinical dysfunction supports diagnosis of MS. VEP may help define the anatomical site of a 


\begin{tabular}{|c|c|}
\hline Clinical Presentation & $\begin{array}{l}\text { Additional Data Needed } \\
\text { for MS Diagnosis }\end{array}$ \\
\hline $\begin{array}{l}2 \text { attacks; objective } \\
\text { clinical evidence } \\
\text { of } \geq 2 \text { lesions }\end{array}$ & None \\
\hline $\begin{array}{l}2 \text { attacks; objective } \\
\text { clinical evidence of } \\
1 \text { lesion }\end{array}$ & $\begin{array}{l}\text { Dissemination in space, demonstrated by: } \\
\text { - MRI, or } \\
\text { - } \geq 2 \text { MRI-detected lesions consistent with } \\
\text { MS plus positive CSF, or } \\
\text { - Await further clinical attack implicating a } \\
\text { different site }\end{array}$ \\
\hline $\begin{array}{l}1 \text { attack; objective clinical } \\
\text { evidence of } 2 \text { lesions }\end{array}$ & $\begin{array}{l}\text { Dissemination in time, demonstrated by: } \\
\text { - MRI, or } \\
\text { - Second clinical attack }\end{array}$ \\
\hline $\begin{array}{l}\text { attack; objective clinical } \\
\text { evidence of } 1 \text { lesion } \\
\text { (monosymptomatic } \\
\text { presentation; clinically } \\
\text { isolated syndrome) }\end{array}$ & $\begin{array}{l}\text { Dissemination in space, demonstrated by: } \\
\text { - MRI, or } \\
\text { - } 2 \text { MRI-detected lesions consistent with MS } \\
\text { plus positive CSF, and } \\
\text { Dissemination in time, demonstrated by: } \\
\text { - MRI, or } \\
\text { - Second clinical attack }\end{array}$ \\
\hline $\begin{array}{l}\text { Insidious neurological } \\
\text { progression suggestive } \\
\text { of MS }\end{array}$ & $\begin{array}{l}1 \text { year of disease progression (retrospectively } \\
\text { or prospectively determined) and } 2 \text { of the } \\
\text { following: } \\
\text { - Positive brain MRI ( } 9 \text { T2 lesions or } 4 \text { T2 } \\
\text { lesions with positive VEP) } \\
\text { - Positive spinal cord MRI ( } 2 \text { focal T2 lesions) } \\
\text { - Positive CSF }\end{array}$ \\
\hline
\end{tabular}

Source: Polman CH, et al. Ann Neurol. 2005;58:840-46.22

$C S F=$ cerebral spinal fluid; VEP = Visual evoked potentials.

2005 Revised McDonald Diagnostic Criteria.

In 2002, the International Panel on the Diagnosis of Multiple Sclerosis published criteria for MS that have been used widely but have undergone continual testing and debate. The original recommendations defined the traditional MS diagnostic criteria as 2 attacks of disease separated in space and time, but added specific MRI, CSF, and evoked potential findings to identify the second attack. ${ }^{21}$ Results from these modalities are used in conjunction with established clinical criteria to place the patient in 1 of 3 possible categories: MS, possible MS, or not MS.

In 2005, an international panel was assembled to update the McDonald Diagnostic Criteria to include new evidence-based recommendations that speed diagnosis without compromising accuracy. ${ }^{22}$ The core of the McDonald Diagnostic Criteria did not change; updated information on MRI data refined reliable imaging parameters. The original guidelines focused on contrast-enhancing lesions; the revised recommendations base an MS diagnosis on dissemination in time as indicated by new MRI-defined T2 lesions compared with a reference scan 30 days earlier. The revised criteria also describe how spinal cord lesions may identify MS and refute the need for CSF criteria when appropriate MRI brain and spinal cord findings are evident. lesion in areas not easily visualized by imaging. ${ }^{20}$

In order to refine and simplify the diagnosis of MS, an international panel was assembled in 2002 to investigate and eventually publish criteria for MS. These original criteria have been used widely but have undergone repeated testing and debate. The original recommendations defined the traditional MS diagnostic criteria as 2 attacks of disease separated in space and time but added specific MRI (magnetic resonance imaging), CSF, and evoked potential findings to identify the second attack. ${ }^{21}$ Results from these diagnostic modalities are used in conjunction with established clinical criteria to place the patient in 1 of 3 possible categories: MS, possible MS, or not MS. These criteria are referred to as the McDonald Criteria.

In 2005, another international panel was assembled to update the McDonald Diagnostic Criteria to include new evidence-based recommendations that speed diagnosis without compromising accuracy. ${ }^{22}$ The core of the McDonald Diagnostic Criteria did not change; updated information on MRI data refined reliable imaging parameters. The original guidelines focused on contrast-enhancing lesions; the revised recommendations base an MS diagnosis on dissemination in time as indicated by new MRI-defined T2 lesions compared with a reference scan 30 days earlier. The revised criteria also describe how spinal cord lesions may identify MS and refute the need for CSF criteria when appropriate MRI brain and spinal cord findings are evident (Table 1).

Debate \#1: When and How Should Treatment Be Initiated in the Newly Diagnosed Patient With Multiple Sclerosis?

Management of MS involves 2 distinct therapeutic approaches. First, relapse prevention is paramount, and this is achieved through the use of immunomodulatory, or disease-modifying, agents (DMT). These agents include interferon formulations, glatiramer acetate, natalizumab, and mitoxantrone, all of which are described in Table 2. The second therapeutic approach involves the use of medication therapy to combat the complications of MS which include spasticity, urinary dysfunction, cognitive issues, and other complications. Since these complications do not typically occur in the newly diagnosed patient, these agents will not be discussed in further detail here.

Exactly when to initiate therapy with a DMT in the newly diagnosed MS patient has been a matter of debate. ${ }^{23}$ The main reason for this debate is that the initial symptoms of MS may be somewhat nonspecific, and it may be difficult to make a diagnosis based upon clinical symptoms alone without supportive diagnostic methods. However, with the use of complementary diagnostic methods as previously described, it is now easier to make a definitive diagnosis of MS and to subsequently initiate treatment with a DMT. Initiating therapy for MS does involve, however, the recognition of the initial MS exacerbation, known as the clinically isolated syndrome (CIS). 


\section{FIGURE 3 Three-Year Natalizumab Studya}

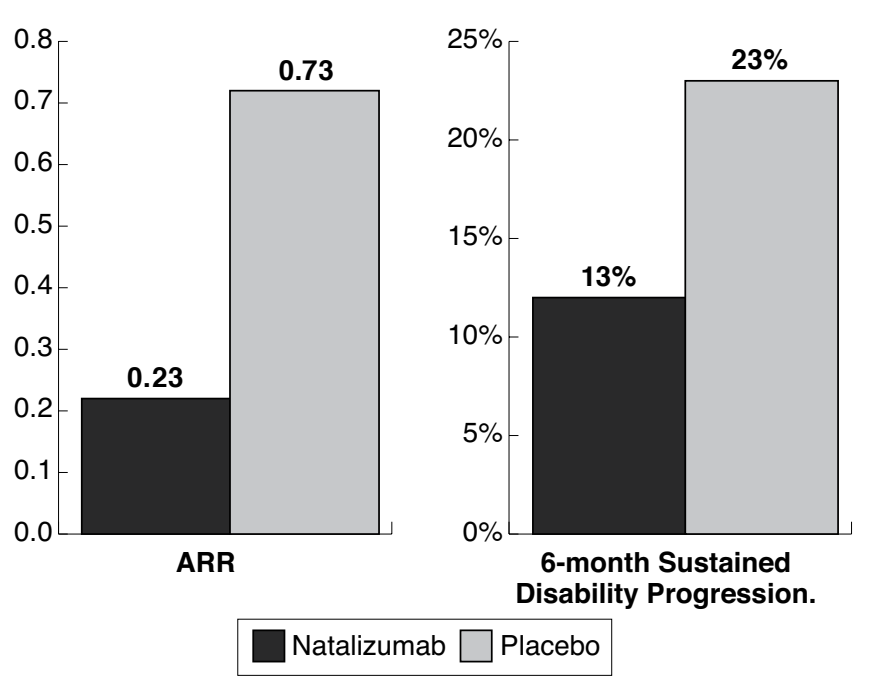

an both analyses, data from natalizumab at 3 years; data from placebo at 2 years. Source: Unpublished data: O'Connor PW, et al. Poster presented at the 59th Annual Meeting of the American Academy of Neurology. ${ }^{34}$

$A R R=$ annualized relapse rate

( $\mathrm{n}=154)$ by SC injection once weekly. ${ }^{29}$ In this study, IFN $\beta-1 \mathrm{a}$ was administered at a lower dosage than is typically given for treatment of MS. Neurological and clinical assessments were conducted every 6 months and brain MRI scans every 12 months. Results from the study showed that the active treatment group had a lower probability of developing CDMS (34\% for IFN $\beta-1$ a versus $45 \%$ for placebo; $P=0.047$ ). The time at which $30 \%$ of the patients had converted to clinically definite MS was significantly longer for the IFN $\beta$-la group compared to the placebo group (569 days vs. 252 days, $P=0.034$ ). Active treatment with IFN $\beta-1 a$ also resulted in a significant reduction in the number of new T2-weighted lesions $(P<0.001)$ and changes in $\mathrm{T} 2$ lesion volume $(P=0.002){ }^{29}$

CHAMPS. The CHAMPS study was a 3-year study that enrolled 383 patients with a first isolated, well-defined neurologic event consistent with demyelination and involving the optic nerve, spinal cord, brain stem, or cerebellum, as well as at least 2 silent brain lesions on MRI scans. ${ }^{30}$ All patients received $1 \mathrm{gm}$ of methylprednisone IV per day for 3 days followed by $1 \mathrm{mg}$ per $\mathrm{kg}$ oral prednisone for 11 days with a 4-day tapering period. Patients were randomized after the IV methylprednisone course to receive weekly intramuscular (IM) injections of IFN $\beta$-la $30 \mathrm{mcg}(\mathrm{n}=193)$ or placebo $(n=190)$. The active treatment group had a significantly lower cumulative probability of developing CDMS compared to placebo (rate ratio $=0.56,95 \% \mathrm{CI}=0.38-0.81$ ); at 3 years the probability was $35 \%$ with IFN $\beta$-la versus $50 \%$ with placebo. At 18 months, patients in the IFN $\beta$-la treatment group also had a significantly greater reduction in the volume of brain lesions, fewer new or enlarging lesions, and fewer Gd-enhancing lesions compared to the placebo group $\left(P<0.001\right.$ for all measures). ${ }^{30}$

Long-Term Follow-Up of CIS Trials. Since the original 4 trials described above were no more than 3 years in duration, the effects of continued DMT on the development of CDMS was not known. Two of the initial CIS studies, CHAMPS and BENEFIT, were continued for a longer duration in order to answer this question. In both the CHAMPIONS (the name of the CHAMPS extension study) and BENEFIT extension studies, patients who originally received active treatment were continued on this treatment (the "early treatment" group), and those that received placebo in the original study protocol were transitioned to active treatment (the "delayed" treatment group). This was done to determine if early treatment results in any long-term advantages. In both studies, it was apparent that early treatment resulted in fewer patients developing clinically definite MS. Specifically, in CHAMPIONS, there was a 57\% risk reduction of developing CDMS at 5 years for the immediate treatment group versus the delayed treatment group. ${ }^{31}$ In the BENEFIT study, there was a $40 \%$ risk reduction of developing CDMS at 3 years for the immediate treatment group versus the delayed treatment group. ${ }^{32}$ The significance of these results is that continued therapy with DMT in patients with CIS can result in sustained reductions in the risk of developing CDMS, and in fact, these agents can delay progression to CDMS by 30 to 36 months.

Trials of Other DMTs. The AFFIRM trial was a placebocontrolled, 2-year study of 942 patients with RRMS who were randomized to receive natalizumab $300 \mathrm{mg}(\mathrm{n}=627)$ or placebo $(n=315)$ by IV infusion every 4 weeks. ${ }^{33}$ After 2 years, natalizumab was reported to significantly reduce the risk of sustained progression of disability by $42 \%(P<0.001)$. The cumulative probability of progression was $17 \%$ and $29 \%$ in the natalizumab and placebo groups, respectively. Natalizumab also led to an $83 \%$ reduction in the number of new or enlarging hyperintense brain lesions, and there were 92\% fewer lesions in the natalizumab group $(P<0.001) .^{33}$ Data from the 3-year open-label extension analysis from AFFIRM presented at the AAN annual meeting in 2007 confirmed the continued effect of natalizumab on relapses and disability progression and are presented in Figure 3. ${ }^{34}$

The utility of mitoxantrone was recently studied in 194 patients with RRMS or SPMS. In this study, patients were randomized to receive placebo or mitoxantrone $\left(12 \mathrm{mg} / \mathrm{m}^{2}\right)$ every 3 months for 2 years. ${ }^{35}$ Compared with the placebo group at 2 years, patients receiving mitoxantrone experienced significant benefits for the primary outcome $(P<0.001)$ and the preplanned univariate analyses of the following measures: (a) change in $\operatorname{EDSS}(P=0.019)$; (b) change in ambulation index $(P=0.031)$; (c) adjusted total number of treated relapses $(P<0.001)$; (d) time to first treated relapse $(P<0.001)$; and $(e)$ change in standardized neurological status $(P=0.027)$. Adverse events that were significantly more common in the mitoxantrone group included nausea, alopecia, UTIs, menstrual disorders and amenorrhea in women, and leucopenia. ${ }^{35}$ 


\section{Comparative Trials of DMTs in Multiple Sclerosis}

Given that all of the previously described DMTs seem to be effective, it becomes important to determine which agent to choose when initiating therapy. To address this issue, several studies have been performed that compare available agents used in the treatment of MS.

INCOMIN. The INCOMIN trial was a 2-year prospective trial comparing treatment with IFN $\beta$-la $30 \mathrm{mcg}$ administered by IM injection once weekly ( $\mathrm{n}=92)$ to IFN $\beta$-1b $250 \mathrm{mcg}$ administered by SC injection every other day $(n=96){ }^{36}$ The results of this study showed that over 2 years significantly more patients in the IFN $\beta$-lb group remained relapse-free compared to patients in the IFN $\beta$-la group ( $51 \%$ vs. $39 \%, P=0.03)$. In addition, more patients being treated with IFN $\beta-1 b$ remained free from new T2 lesions compared to the IFN $\beta$-la treated group (55\% versus 26\%, $P<0.001$ ). The authors noted that there was no difference in compliance between the 2 study groups, indicating that the frequency of dosing and the concentration used may act together to affect disease activity and progression in patients with RRMS. ${ }^{36}$

EVIDENCE. The EVIDENCE study was a 24-week randomized clinical trial of 677 patients comparing the efficacy and safety of 2 IFN formulations and schedules: IFN $\beta-1 \mathrm{a}(44 \mathrm{mcg})$ administered by SC injection 3 times weekly or IFN $\beta-1$ a (30 $\mathrm{mcg}$ ) administered by IM injection once weekly. ${ }^{37}$ Patients were evaluated every 4 weeks during the treatment period and also at weeks 36 and 48 . The results showed that more patients on the 3 times weekly regimen were relapse-free at 24 weeks compared with the once weekly regimen ( $75 \%$ vs. $63 \%$ ). The odds ratio for remaining relapse-free was 1.9 at 24 weeks $(P<0.001)$ and 1.5 $(P=0.009)$ at 48 weeks, favoring IFN $\beta$-la 44 mcg 3 times weekly. Patients on the 3 times weekly IFN $\beta$-la regimen also had fewer active lesions on MRI scans than those on the once weekly regimen at both 24 and 48 weeks $(P<0.001){ }^{37}$ Results from this early study strongly suggest that specific treatment regimens may have an impact on efficacy.

European IFN $\beta$-la Dose-Comparison Study. The European IFN- $\beta$-la Dose-Comparison Study was a 36-month trial that randomized 802 patients to treatment with either IFN $\beta$-la $30 \mathrm{mcg}$ $(n=402)$ or IFN $\beta-1$ a $60 \mathrm{mcg}(\mathrm{n}=400)$, both administered by IM injection once weekly. Subjects were evaluated every 3 months for efficacy and adverse events. At 36 months, there was no difference between the 2 groups in disability progression, which was the primary endpoint of the study. Although both dosages of IFN $\beta$-la were well tolerated, the group with the higher IFN $\beta$-la dose (60 mcg) experienced slightly higher incidences of flu-like symptoms and muscle weakness. ${ }^{38}$

REGARD. The REGARD study was a 96-week randomized study of 764 patients comparing treatment with IFNß-1a $44 \mathrm{mcg}$ 3 times weekly to GA 20 mg once daily in patients with RRMS. ${ }^{39}$ Clinical assessments were done at 4, 12, and 24 weeks and every 24 weeks thereafter. Figure 4 shows the results for the time to first relapse, the primary outcome from this trial. There was no sig-

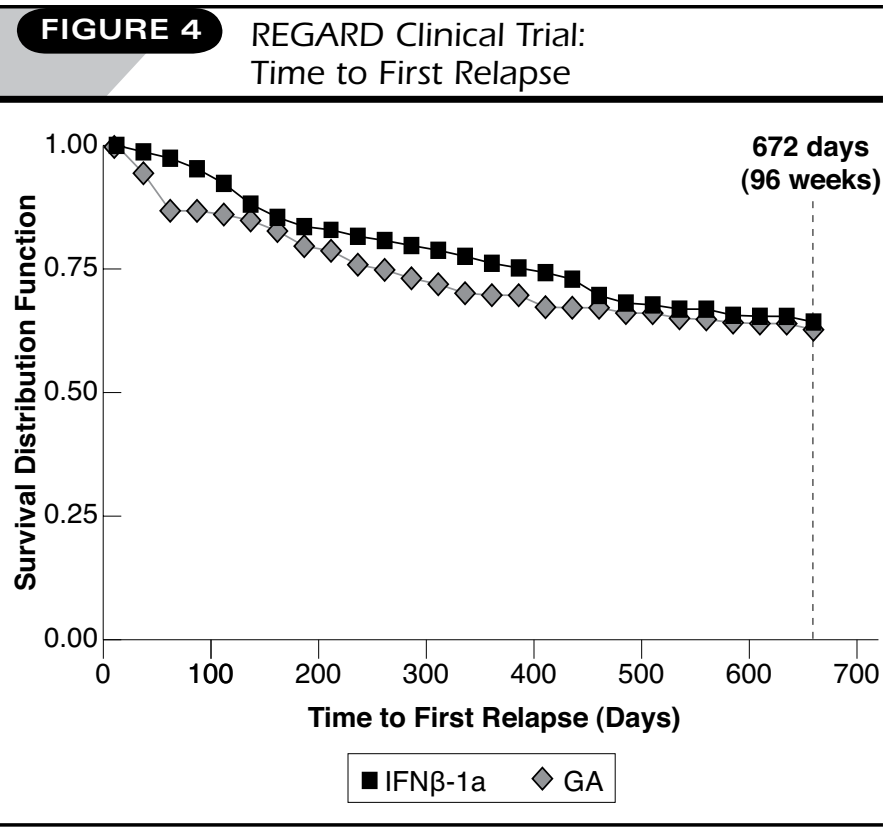

Source: Mikol DD, et al. Lancet Neurol. 2008;7:903-14.39

nificant difference between the 2 treatment groups over 96 weeks with respect to the rate of development of first relapse (hazard ratio[HR] $=0.943, P=0.643$ ). However, the authors noted that there was much less active disease than expected, with approximately $45 \%$ fewer relapses seen. Specifically, 258 out of 764 patients (33.8\%) experienced 1 or more relapses during the course of the trial, whereas, in the planning of the trial, it was predicted that 460 patients would experience a relapse. Therefore, although no difference was seen between the 2 study groups, the lower number of relapses may have impacted the ability to detect a treatment difference. ${ }^{39}$

BEYOND. The BEYOND trial is a 2-year, Phase III, randomized, multicenter study of 2,244 patients with RRMS that compared GA 20 mg daily ( $\mathrm{n}=448$ ) versus IFNß-1b 250 mcg 3 times weekly $(\mathrm{n}=897)$ versus IFNß-1b $500 \mathrm{mcg} 3$ times weekly $(n=899)$, all 3 agents being administered by SC injection. The primary efficacy outcome was relapse risk, and Figure 5 shows results from this trial, which were presented at the AAN annual meeting in 2008. The annualized relapse rate was reduced by almost $80 \%$ in each treatment arm; however, there were no significant differences between the 3 treatment groups. ${ }^{40}$

\section{Conclusions from DMT Trials}

It is clear from the data presented above that GA, both interferons, and the other DMTs are all effective in reducing the risk of relapses, as well as other outcomes. It is also important to note that early treatment with either group of agents is effective in reducing the risk of conversion of CIS to CDMS. Because of this data, it may be necessary to consider other factors when 


\section{FIGURE 5}

BEYOND Clinical Trial:

Primary Efficacy Endpoint

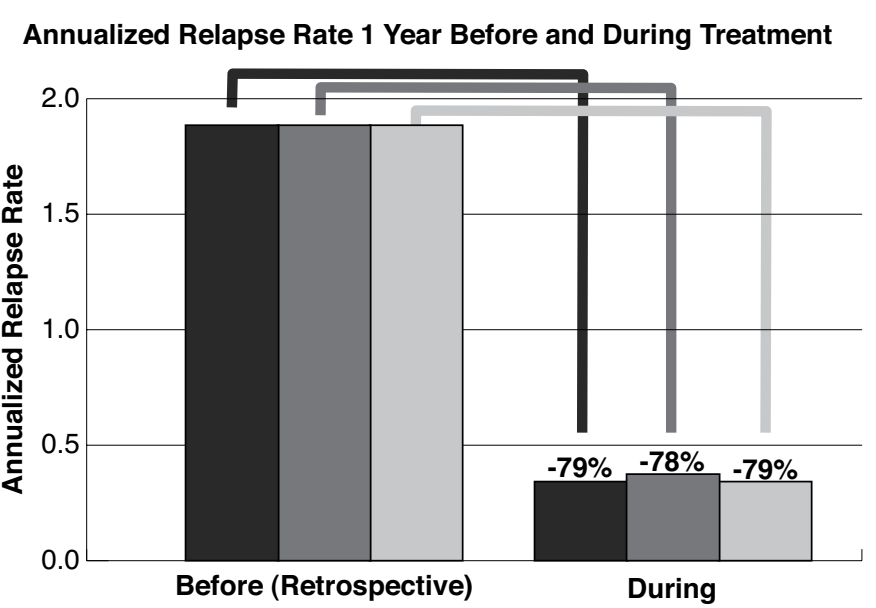

IFN $\beta-1 \mathrm{~b} 500 \mathrm{mcg} \square$ IFNß-1b $250 \mathrm{mcg} \square$ Glatiramer acetate

Source: Unpublished data: O'Connor P, et al. 40

determining which agent to use in the treatment of the patient with MS, such as side effect profiles, ease of administration, and patient preference. While it is fortunate that patients with MS have several effective therapies available, it is unfortunate that the data thus far has not resolved the debate regarding which is the best agent to use with each patient.

\section{Debate \#2: How Can Medication Adherence Be Improved in Multiple Sclerosis?}

Medication adherence is important for patients with MS but is a challenging issue. Many factors may impact medication adherence, including adverse effects of the DMTs. While all DMTs can produce some type of adverse effects, there are some common and specific issues to address when utilizing these agents.

\section{Adverse Effects of DMTs}

Injection site reactions and flu-like symptoms are common side effects seen with the use of interferons. In the BENEFIT trial of IFN $\beta-1 b$ ( $250 \mathrm{mcg}$ SC every other day), injection site reactions were reported in $48.3 \%$ of subjects over the course of the study compared with $8.5 \%$ of those who received placebo. Similarly, flu-like syndrome occurred in $44.2 \%$ of subjects receiving IFN $3-1$ lb compared to $18.2 \%$ of placebo-treated patients. Both injection site reactions and flu-like syndrome were more common in the first year of treatment and less prevalent during the second year of treatment, indicating that these side effects tend to resolve with continued treatment. ${ }^{28}$

In the EVIDENCE trial comparing 2 formulations and schedules of IFN $\beta-1$ a, injection site reactions were reported in $24.5 \%$ of patients receiving IFN $\beta$-la 44 mcg 3 times weekly compared with $8.3 \%$ of patients treated with IFN $\beta-1$ a 30 mcg weekly $(P<0.001)$. It should be noted that the IFN $\beta-1$ a $44 \mathrm{mcg}$ formulation was administered by SC injection, while IFN $\beta$-la 30 mcg weekly was given IM. Flu-like syndrome occurred in $12.4 \%$ and $14.5 \%$ of subjects in the IFN $\beta$-la 44 mcg and IFN $\beta$-la 30 mcg groups, respectively. ${ }^{37}$

Similar results were reported in the INCOMIN trial, comparing IFN $\beta-1 \mathrm{a}$ (30 mcg IM qw) with IFN $\beta$-lb (250 mcg SC every other day). Injection site reactions were seen in $37 \%$ of patients receiving $250 \mathrm{mcg}$ SC versus $8 \%$ in the $30 \mathrm{mcg}$ IM group. In this trial, flu-like syndrome was observed in slightly more than $75 \%$ of patients in both treatment groups. ${ }^{36}$

Depression is also commonly seen with the use of interferons. For example, depression reported by patients in the EVIDENCE and INCOMIN trials ranged from $5 \%$ to $22 \%$ and was similar between IFN $\beta$ treatment groups within individual studies. ${ }^{36,37}$ However, since patients with MS are at increased risk for depression, it may be difficult to ascertain what the causative factor is if the patient becomes depressed. In the BENEFIT trial, the incidence of depression was similar in patients treated with IFN $\beta-1 b$ (10.3\%) compared to placebo (11.4\%). ${ }^{28}$

Asymptomatic hepatic transaminase abnormalities, as well as hematologic abnormalities, may also occur with interferons. In the INCOMIN trial, increased liver enzymes were reported in $26 \%$ and $23 \%$ of patients receiving IFN $\beta-1 \mathrm{a}(250 \mathrm{mcg})$ and IFN $\beta$ - $1 \mathrm{~b}\left(30 \mathrm{mcg}\right.$ ), respectively. ${ }^{36}$ It is therefore recommended that patients receiving interferons have regular monitoring of hepatic function, as well as complete blood counts (CBC) taken throughout their treatment. ${ }^{41}$

Local injection site reactions are also common with GA. For example, injection site inflammation (49\% vs. $11 \%$ ), pruritis ( $40 \%$ vs. $6 \%$ ), and swelling ( $27 \%$ vs. $10 \%$ ) were more frequently reported with GA treatment compared with placebo in earlier clinical trials. ${ }^{42}$ However, in the REGARD study published in 2008, the prevalence of injection site inflammation (30\%), pruritis (20\%), and swelling (11\%) with GA treatment were somewhat lower. ${ }^{39}$ Because GA is administered daily, injection site rotation is especially important. Transient postinjection systemic reactions occur in approximately 10\% of patients with GA and are characterized by the sudden onset of symptoms such as chest pain, flushing, dyspnea, palpitations, and anxiety. Postinjection systemic reactions typically occur within minutes of administration and resolve within 30 minutes. Lipoatrophy can also occur at the injection site, especially when the same area is used repeatedly. As noted earlier, patients should rotate their injection sites to prevent this complication. ${ }^{41,42}$

In the AFFIRM trial, adverse effects that were more common with natalizumab compared to placebo were fatigue (27\% vs. $21 \%, P=0.048)$ and allergic reactions (9\% vs. $4 \%, P=0.012){ }^{33}$ Asymptomatic elevation in hepatic transaminases and increased rates of infection may also occur with natalizumab. Allergic/ 
infusion reactions can consist of rash, headaches, chills, fever, hypotension, dyspnea, chest pain, and in rare cases, anaphylaxis. Patients who experience the latter should discontinue use. ${ }^{41,43} \mathrm{An}$ additional concern with the use of natalizumab is the potential for development of progressive multifocal leukoencephalopathy (PML), which is an opportunistic viral infection of the brain that usually leads to severe disability or death. Several cases of PML in patients with MS treated with natalizumab alone or combination with other agents have been reported in the literature. ${ }^{44,45}$ The risk of PML has been estimated at 1 person for every 1,000 patients treated for an average of 17.9 months, based upon the incidence observed in a pooled clinical trial cohort. ${ }^{46}$ Since symptoms of PML sometimes mimic those of MS, it may be difficult to ascertain if patients are experiencing an MS relapse or PML. Natalizumab is only available through a special restricted distribution program called the TOUCH Prescribing Program, under which only prescribers, infusion centers, and pharmacies registered with TOUCH are able to prescribe, distribute, or infuse natalizumab.

The use of mitoxantrone may result in an increased risk of cardiovascular toxicity, so a maximum lifetime dose of 140 $\mathrm{mg} / \mathrm{m}^{2}$ is recommended. ${ }^{47}$ Mitoxantrone therapy has also been linked to hematologic toxicity including leukopenia, anemia, and thrombocytopenia, as well as rare reports of acute leukemia. Accordingly, close monitoring for both cardiac and hematologic toxicity is essential for patients receiving mitoxantrone. ${ }^{41,47}$

In light of the above data, it is clear that adverse effects of the DMTs are not to be minimized, and certain agents may be more problematic than others. Accordingly, both the interferons and GA are generally considered as first line agents for patients with MS, with natalizumab and mitoxantrone reserved for those who fail initial therapy.

\section{Other Issues Related to Medication Adherence}

There are additional issues related to medication adherence in the patient receiving DMT for MS. One such issue is education. It is imperative that patients with MS be educated not only on their disease process, but the rationale for treatment. A frequent concern of newly diagnosed MS patients is that they are being asked to administer medications when they have no symptoms, that is, during periods of no disease activity. In this case, it is important that patients understand that DMT is designed to prevent relapses, thereby reducing the chances that MS will progress. Understanding this aspect of the disease will guarantee understanding as to why early treatment is necessary.

Aichmophobia, or fear of needles, may be another barrier to adherence to DMT therapy, since patients generally have difficulty with self-injection. As newer oral therapies come to market, this barrier may be reduced or even eliminated. Patient expectations with regard to treatment efficacy may also present a barrier, as initial high expectations may be met with low treatment efficacy. Specifically, since DMTs do not reverse pre-existing neurologic damage, patients may wonder why they should use these drugs. As mentioned above, the proper role of DMTs must be emphasized so that patients remain on therapy.

Reasons for adherence to DMT in MS have been studied extensively. Mental illness, specifically depression, has been postulated to have an affect on adherence. Mohr et al. noted that $41 \%$ of patients reported new or increased depression within 6 months of starting interferon treatment, and patients who experienced symptoms of depression were more likely to discontinue treatment. Accordingly, it was suggested that treating depression may increase adherence to disease-modifying therapy. ${ }^{48}$

A perceived lack of efficacy is another commonly studied reason for nonadherence. In one study, Clerico noted that the most frequent cause of stopping treatment was patients' perceived lack of efficacy, and that most treatment withdrawals occurred during the first year, shortly after therapy had been started. ${ }^{49}$ In another study of 632 patients conducted in Spain, approximately $17 \%$ of patients were nonadherent to DMT therapy. Of those, approximately half stopped DMT because of lack of efficacy, and $25 \%$ stopped because of side effects. ${ }^{50}$ Interestingly, the degree of disability at the start of the study was a major factor in predicting interruption of therapy.

Several studies have been conducted that specifically evaluated predictors of adherence to GA therapy. In one study, 4 significant predictors of adherence to GA therapy were identified: self-efficacy, hope, a supportive relationship with the physician, and lack of prior use of DMT. ${ }^{51}$ In a subsequent analysis, several differences were noted between those who were adherent and nonadherent to DMT therapy. Nonadherent patients had a greater level of disability, spasticity, and fatigue; whereas adherent patients had greater levels of self-efficacy and a higher level of education. In this study, patients were considered adherent if they remained on therapy 1 year after therapy initiation. ${ }^{52}$

Data from these and other studies illustrate several key points with respect to DMT adherence in MS. First, clear and convincing education is necessary so that patients understand why they are being treated and what adverse effects to expect. Second, patient concerns about self-injection must be evaluated and necessary encouragement provided. Third, the presence of pre-existing depression or strongly held opinions about DMT must be ascertained, as these may reduce adherence to DMT. Finally, a holistic approach to evaluating a patient's readiness to begin DMT is important, as certain individual characteristics, including selfefficacy and hope, may be associated with improved adherence.

\section{Optimizing Treatment Adherence in Multiple Sclerosis}

Treatment optimization in MS is defined as the process used to ensure the best possible clinical, subclinical (e.g., MRI), psychosocial, and quality of life outcomes for patients with MS using DMTs. This involves the following components: effective initial assessment and patient selection; appropriate treatment selection; comprehensive patient education; self-injection 
training; ongoing monitoring of clinical, radiologic, laboratory, and psychosocial parameters; and assessment of treatment adherence. ${ }^{53}$ The primary management goal is obtaining the best possible overall outcome for each patient.

In 2004, a group of international MS experts were convened to evaluate optimization of treatment success for patients with MS. ${ }^{54}$ While a multitude of relevant parameters were examined, 3 main factors were identified that were strongly associated with therapeutic outcomes for patients with MS: rate and severity of relapses, assessment of disability, and MRI activity. In evaluating a patient's clinical status, each of these parameters were classified as notable, worrisome, or actionable, and a composite of the 3 parameters was used to dictate the appropriate therapeutic action for a given patient, such as changing DMTs. The consensus group did also note, however, that additional factors should be considered in MS therapy optimization, but that for many of these factors, there may be an absence of methods of assessment. Accordingly, while many factors should be considered when optimizing treatment for a patient with MS, the parameters described above may provide a useful framework with which to consider therapeutic options in MS. ${ }^{54}$

\section{Debate \#3: What Factors Should Be Considered in the Patient Receiving Long-Term Therapy for Multiple Sclerosis?}

Once a patient initiates treatment with a DMT for MS, this treatment should be continued indefinitely. According to expert consensus of the National Clinical Advisory Board of the National MS Society, it is generally recommended that patients with MS receive treatment indefinitely unless they are unable to tolerate therapy, there is a clear lack of clinical benefit, or they experience intolerable side effects. ${ }^{26}$ Because of this recommendation, several concerns have surfaced that must be considered in the patient who is on long-term DMT for MS.

Pregnancy and MS. Based upon previous studies, there is no evidence that pregnancy affects the long-term course of MS, and pregnancy does not appear to accelerate the course or amplify the negative effects of MS. There is also no evidence that MS impairs fertility or leads to congenital malformations, stillbirths, or spontaneous abortions..$^{55,56}$ With regard to therapy, however, none of the presently available DMTs has been approved for use by women who are trying to become pregnant, are pregnant, or are nursing. ${ }^{26} \mathrm{GA}$ is the only DMT that has received a category B rating for pregnancy; interferon preparations and natalizumab each have a category $\mathrm{C}$ rating; and mitoxantrone carries a category $\mathrm{D}$ rating. ${ }^{57}$ Mitoxantrone is considered a potential human teratogen because of its mechanism of action and the developmental effects demonstrated by related agents. In animal models, administration of mitoxantrone during pregnancy was associated with fetal growth retardation and premature delivery.47

Following pregnancy, there may be an increase in exacerbation rates for the first 3 to 6 months postpartum, with a relapse risk of approximately $20 \%$ to $40 \%$, but this does not contribute to an increase in long-term disability. ${ }^{55}$ Accordingly, patients should be restarted on DMTs as soon as possible after pregnancy, assuming that they are not breastfeeding. None of the DMTs approved by the Food and Drug Administration are approved for use in nursing women, since it is not known if they are excreted into breast milk. Since studies have indicated that there is no increased relapse risk of MS associated with nursing, women with MS who want to breastfeed should discuss options with their neurologist to determine the best course of action in their individual case.

Neutralizing Antibodies and MS. Neutralizing antibodies (NAbs) are endogenously produced antibodies that may reduce the clinical efficacy of MS therapy. NAbs are known to develop for all currently available interferon beta (IFN $\beta$ ) therapies and natalizumab but have not been shown to develop with use of GA in clinical trials. There is some evidence, at least with IFN $\beta-1 b$ therapy, that NAbs may disappear after a period of time..$^{58,59}$

The potential impact of NAbs has been observed in clinical trials of DMTs. In the REGARD trial, 126 of 386 patients on IFN $\beta$-la therapy (33\%) developed NAbs to interferon at any time during the study. Overall, the presence of NAbs did not have a significant effect on clinical efficacy. However, patients in the MRI subgroup who tested negative for NAbs had fewer T1 Gd-enhancing lesions compared with patients who were NAbpositive at any time during the study, and patients who were NAb-negative throughout the study generally had better clinical outcomes. ${ }^{39}$

In the open-label follow-up of the BENEFIT trial with IFN $\beta-1 b$, NAb activity was detected at least once in 88 of 277 (32\%) patients in the early treatment group and 34 of 173 (20\%) patients in the delayed treatment group. The authors stated that NAb activity had no effect on either relapse-related or disabilityrelated outcomes. In addition, $47 \%$ of patients with NAbs in the early treatment and $24 \%$ of those in the delayed treatment group who tested positive converted to NAb-negative status by 36 months. $^{32}$

Whether or not to test for NAbs is somewhat controversial According to the AAN, it is generally believed that testing is unnecessary if patients are clinically stable, since there is insufficient information on specific recommendations regarding when to test, which test to use, how many tests are necessary, or which cutoff titer to apply. ${ }^{58}$ The European Federation of Neurological Sciences takes a different position, recommending NAb testing at 12 and 24 months of therapy ${ }^{59}$ This group also recommends that measurement of NAbs be performed in specialized laboratories with a validated cytopathic effect assay of MxA production assay using serial dilution of the test sera. If NAbs are detected, it is recommended that DMT be discontinued because of data suggesting that they may compromise therapeutic efficacy. ${ }^{58,60}$

\section{Long -Term Effectiveness of DMT in Patients with Multiple Sclerosis}

As noted earlier, there are a significant amount of data that 
support the long-term use of DMT therapy for MS, with the exception of natalizumab, which has been available for only 3 years. Table 3 summarizes the long-term results of clinical trials of DMTs. Data obtained from these trials have been acquired by different methods, so a direct comparison is not possible. With respect to GA, data have been prospectively gathered, whereas data for the other agents have been gathered retrospectively. The effect that the various DMTs have upon the EDSS score is instructive and supportive of long-term use. Notably, with GA, only $18 \%$ of patients who had MS for over 18 years reached an EDSS score of 6 , and with INF $\beta$-1b and INF $\beta$-1a, an EDSS score of 6 was reached by $45 \%$ and $35 \%$ of patients, respectively, who were treated from 13 to 20 years. With respect to natalizumab, there are limited long-term data and conclusions about its effect upon EDSS scores cannot be drawn. ${ }^{61-65}$

\section{Long-Term Effects of DMT Upon Imaging Data in Multiple Sclerosis}

MRI is frequently utilized to follow clinical status of patients with MS on DMT. When analyzing MRI data, there are different types of lesions that may be associated with ongoing disease activity, such as atrophy, "black holes" (defined as T1 hypointense lesions that persist for 6 months or longer), Gd-enhancement, and T2 lesions. All of these changes correlate with the loss of axons and the occurrence of extensive demyelination and may ultimately be useful markers of neurodegeneration in MS. ${ }^{66}$ Because of the different types of lesions, proper detection of MS-related pathology in the brain may require advanced MRI techniques, since evidence suggests that conventional MRI lacks the specificity required for analyzing the underlying pathology and may fail to capture clinically relevant diffuse occult disease affecting both the cerebral white matter and gray matter. ${ }^{67}$ Studies using advanced MRI techniques (e.g., magnetization transfer, spectroscopy, diffusion imaging, relaxometry techniques) have provided emerging data that suggest these techniques may result in a more sensitive and specific depiction of clinically relevant underlying pathology ${ }^{67}$

The BECOME trial was a prospective study of 75 patients with CDMS who were randomized to GA injection $(n=39)$ or IFN $\beta$-1b injection $(n=36)$ and monitored with monthly MRIs for up to 24 months. Preliminary results for the primary outcome of the BECOME study - the mean number of combined, active, Gd-enhancing lesions (CAL) per patient over 15 monthswere presented at the European Committee for Treatment and Research in Multiple Sclerosis (ECTRIMS) in 2006. ${ }^{68}$ These results showed that the sum of CAL counts through month 15 did not differ between the 2 treatment groups. Follow-up data for 24 months was presented at ECTRIMS in 2007. ${ }^{69}$ The findings indicated that there was no statistically significant difference between the treatment groups with regard to CAL per scan, CAL per month, and newly enhancing lesions per scan. There was also no significant difference between treatment groups in any of the secondary clinical endpoints between the 2 treatment groups,

\section{TABLE 3 Summary of Long-Term Data: Patients Reaching EDSS Milestones}

\begin{tabular}{|c|c|c|c|c|}
\hline & $\begin{array}{c}\text { Disease } \\
\text { Duration } \\
\text { (Years) }\end{array}$ & $\begin{array}{c}\text { Percentage } \\
\text { Reaching } \\
\text { EDSS } 4\end{array}$ & $\begin{array}{c}\text { Percentage } \\
\text { Reaching } \\
\text { EDSS } 6\end{array}$ & $\begin{array}{c}\text { Percentage } \\
\text { Reaching } \\
\text { EDSS } 8\end{array}$ \\
\hline GA 15-year LTFU & $>18.5$ & $38 \%$ & $18 \%$ & $3 \%$ \\
\hline $\begin{array}{l}\text { High-dose IFN } \beta \text {-la } \\
\text { PRISMS } 8\end{array}$ & $\sim 13$ & $26.8 \%$ & $20 \%$ & $\begin{array}{l}\text { Not } \\
\text { reported }\end{array}$ \\
\hline $\begin{array}{l}\text { IFN } \beta \text {-1b 16-Year } \\
(>80)\end{array}$ & $\sim 20$ & $\begin{array}{c}\text { Not } \\
\text { reported }\end{array}$ & $\sim 45 \%$ & $\begin{array}{l}29.4 \% \\
(n=48)\end{array}$ \\
\hline $\begin{array}{l}\text { Low-dose IFN } \beta \text {-la } \\
\text { 8-Year Atrophy }\end{array}$ & 14.3 & $\begin{array}{l}\text { Not } \\
\text { reported }\end{array}$ & $\begin{array}{c}\text { Not } \\
\text { reported }\end{array}$ & $\begin{array}{l}\text { Not } \\
\text { reported }\end{array}$ \\
\hline Natalizumab 2-Year & 5.3 & $\begin{array}{l}\text { Not } \\
\text { reported }\end{array}$ & $\begin{array}{l}\text { Not } \\
\text { reported }\end{array}$ & $\begin{array}{l}\text { Not } \\
\text { reported }\end{array}$ \\
\hline
\end{tabular}

Sources: Weinshenker BG, et al. Brain. 1989;112(Pt 1):133-46. ${ }^{12}$ Ford CC, et al. Mult. Scler. 2006;12:309-20.61 Kappos L, et al. Neurology. 2006;67:944-53.62 Unpublished data: Ebers $G$, et al. ${ }^{63}$ Fisher E, et al. Neurology. 2002;59:1412-20.64 Unpublished data: Ford C, et al. 65

EDSS = Expanded Disability Scale Score; LTFU=long-term follow-up

which included annualized relapse rate, progression of disability (EDSS increase greater than or equal to 1 for 6 months or more), change in hand and leg function and attention, or a change in cognitive function. ${ }^{69}$

Data regarding the impact of DMT on the development of black holes has been studied in a limited fashion. In one study of 239 patients receiving GA, the percentage of new lesions that evolved into black holes was measured using monthly MRIs. A significant reduction in the evolution of new lesions into black holes in GA-treated compared with placebo-treated patients was seen at both 7 months ( $18.9 \%$ vs. $26.3 \%, P=0.04)$ and 8 months (15.6\% vs. $31.4 \%, P=0.002) .^{70}$ In a more recent study of 942 patients receiving natalizumab, there was a $76 \%$ decrease in new black holes and a 92\% decrease in Gd-enhancing lesions. ${ }^{71}$ There is considerably less data with the interferons. ${ }^{66,72}$

The effect of DMT upon brain atrophy has also been evaluated. A 5-year study of patients with RRMS was presented at ECTRIMS in 2007; the study examined the effect of GA, highdose IFN $\beta-1 \mathrm{a}$, and low-dose IFN $\beta$-la upon the development of brain atrophy. The results showed that GA-treated patients demonstrated a significantly lower annualized rate of brain atrophy $(0.47 \%)$ than patients treated with either high-dose $(0.67 \%)$ or low-dose IFN $\beta-1 \mathrm{a}(0.55 \%)(P<0.001)$. The annualized rate of brain atrophy was significantly lower in all 3 treatment groups versus the untreated group $(P<0.001) .^{73}$

The important point of these imaging studies is that MRI should be used in the assessment of the effectiveness of DMT as well as in evaluating patient outcomes. Since there are a number of different MRI manifestations of MS, it is important to be familiar with the differing effects that DMT can have upon these parameters. 


\section{FIGURE 6 Reduction in Relapse Rates After Changing Therapy}

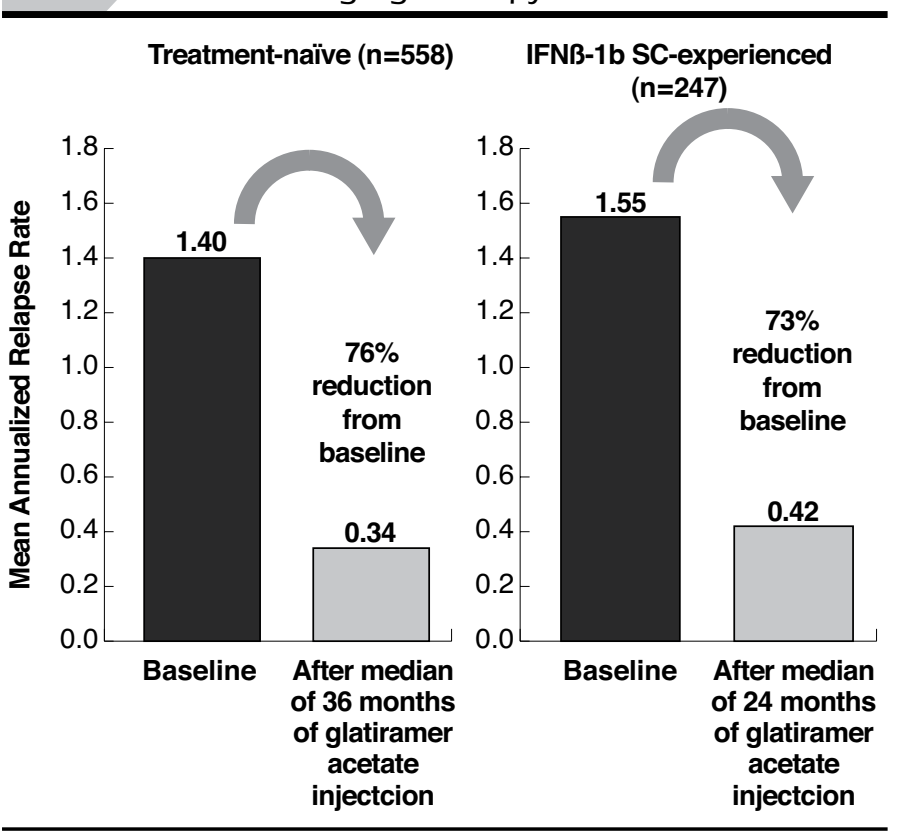

Source: Zwibel HL, et al. Acta Neurol Scand. 2006;113:378-86.77

$S C=$ subcutaneous.

\section{Recognizing and Addressing an Inadequate Response to MS Therapy}

There are presently no established, generally accepted criteria for determining when a patient's response to MS therapy is suboptimal. However, several publications, including an opinion paper by the Clinical Advisory Board of the National Multiple Sclerosis Society ${ }^{26}$ have noted a number of possible markers that should be considered when assessing responses to therapy. One of these markers is the rate of relapse. A suboptimal response to treatment can be defined as either a failure to demonstrate relapse rate reduction after 6 to 12 months of continuous use of a DMT, or experiencing more than 1 relapse per year. Declaring treatment failure based on a single attack while on therapy, or as a result of a relapse that occurs within a few months of initiating treatment, is inappropriate and not justified. Mild sensory relapses that do not cause a disease deficit are less concerning and should not necessarily be considered a reason for switching therapy. In contrast, moderate or severe relapses that result in an incomplete recovery, including worsening of disability, are more likely to be due to suboptimal response. In these situations, switching a patient's therapy should be seriously considered. . $^{26,74-76}$

In addition to frequency of relapses, worsening neurologic impairment may also indicate a suboptimal response to MS therapy. For example, an annual increase in EDSS score of at least 1 point from a previous score of 3.0 to 5.5 , or a 0.5 -point increase from a previous score of 6.0 or greater in the absence of clinical attacks indicates progressive neurologic impairment. Other signs of increasing neurologic impairment (e.g., deterioration of cognitive, urogenital, or sexual dysfunction) sufficient to disrupt daily activities may be a sign that a particular therapy is not achieving its desired results. ${ }^{26,74-76}$

\section{Recognizing the Need to Switch Therapies}

If a patient with MS has what is deemed to be an inadequate response to therapy, then switching to another DMT should be considered. Several studies have been conducted to examine the need for and results of switching from one DMT to another. In one study, Zwibel et al. evaluated 805 patients with MS who fell into 2 groups: (1) patients who had been on high-dose IFN $\beta$-1b therapy, had discontinued due to suboptimal efficacy or persistent toxicity, and then were switched to GA; and (2) treatmentnaive patients. ${ }^{77}$ The mean annualized relapse rates during the 2 years prior to the study were 1.40 in the treatment-naive group and 1.55 in the IFN $\beta$-lb-experienced group. Compared with the 2 years prior to study entry, the annual relapse rates decreased by approximately $75 \%$ in both cohorts. In the treatment-naive cohort, there was a mean $76 \%$ relapse rate reduction from baseline after a median of 36 months of GA therapy. In the IFNß-1b subcutaneous-experienced cohort, there was a mean $73 \%$ relapse reduction from baseline after a median of 24 months of GA therapy (Figure 6). ${ }^{77}$

Another study conducted by Caon et al. evaluated 85 patients with MS who had switched to GA after discontinuing therapy with low-dose IFN $\beta$-la due to either suboptimal efficacy or persistent toxicity. ${ }^{78}$ At the beginning of this study, the mean annualized relapse rate was 1.41. After a mean of 19.7 months of IFN $\beta$-1a treatment, the annualized relapse rate had been reduced by $13 \%$ from baseline to $1.23(P=0.005)$. After a mean of 37.5 months of treatment with GA injection (range of 36 months to 42 months), the mean annualized relapse rate had been significantly reduced by $57 \%$ to $0.53(P<0.001) .^{78}$

A more recent prospective, longitudinal study from Argentina included 114 patients with RRMS who failed first-line monotherapy and switched treatments after 3 years. ${ }^{79}$ The primary outcome measure was the annualized relapse rate, and secondary outcome measures were the proportion of relapse-free patients and the median change in EDSS scores. Patients were switched from either: (a) IFN $\beta$ to GA ( $n=52)$; (b) from GA to IFN $\beta$ ( $n=16)$; (c) from low-dose to high-dose IFN $\beta$ ( $n=31)$; or (d) from IFN $\beta$ to mitoxantrone $(n=15)$. In the 3 years after switching therapies, the annualized relapse rate reductions ranged from a high of $77 \%$ in the group that switched from IFN $\beta$ to GA, to $57 \%$ in patients who switched between IFN $\beta$ doses (Figure 7). The proportion of relapse-free patients varied from $56 \%$ to $81 \%$. The median EDSS scores remained stable in all groups except the GA to IFN $\beta$ switchers. The authors concluded that patients who failed first-line immunomodulatory therapy generally benefited from switching to another class of immunomodulatory therapy ${ }^{79}$ 


\section{FIGURE 7 Reductions in Relapse Rates After Changing Therapy}

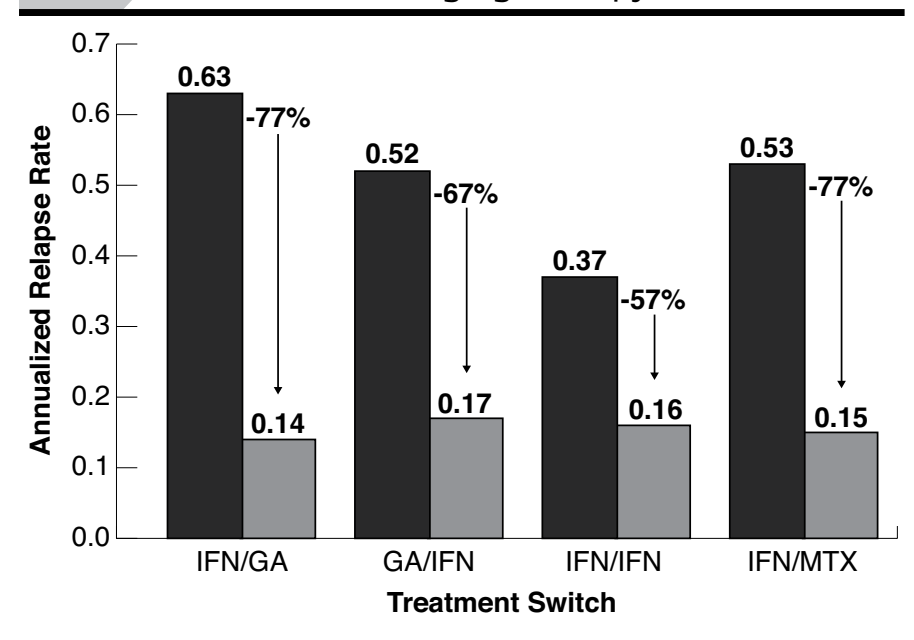

Source: Carra A, et al. Eur J Neurol. 2008;15:386-93.79

IFN=interferon; $G A=$ glatiramer acetate; MTX= mitoxantrone.

\section{Conclusions}

Despite the existence of many effective therapies for MS, there still remain numerous clinical debates regarding the optimal management of patients with this disease. Determining the most effective agent to utilize, and when to utilize it, may be problematic. Determining how to improve patient adherence is a large issue that requires the efforts of multiple stakeholders. Understanding the long-term effects of therapy with DMTs, as well as how to monitor patients on these agents poses a challenge as well. As we move forward and improve efforts at management and monitoring for patients with MS, we will continue to experience challenges that cause us to debate the best course of action for this group of vulnerable patients.

\section{REFERENCES}

1. Trapp BD, Peterson J, Ransohoff RM, Rudick R, Mörk S, Bö L. Axonal transection in the lesions of multiple sclerosis. N Engl J Med. 1998;338(5):278-85.

2. DeLuca GC, Williams K, Evangelou N, Ebers GC, Esiri MM. The contribution of demyelination to axonal loss in multiple sclerosis. Brain. 2006;129(Pt 6):1507-16.

3. Zwibel H. Practical issues in multiple sclerosis: optimal patient management strategies. J Manag Care Med. 2007;10(4):34-37.

4. Cardoso E, Fukuda T, Pereira J, et al. Clinical and epidemiological profile of multiple sclerosis in a reference center in the state of Bahia, Brazil. Arq Neuropsiquiatr. 2006;64(3B):727-30.

5. Frohman E. Multiple sclerosis. Med Clin North Am. 2003;87(4):867-97.

6. Hogancamp WE, Rodriguez M, Weinshenker BG. The epidemiology of multiple sclerosis. Mayo Clin Proc.1997;72(9):871-78.

7. Ascherio A, Munger K. Epidemiology of multiple sclerosis: from risk factors to prevention. Semin Neurol. 2008;28(1):17-28.
8. Fotheringham J, Jacobson S. Human herpesvirus 6 and multiple sclerosis: potential mechanisms for virus-induced disease. Herpes. 2005;12(1):4-9.

9. Cohen J, Rensel M. The differential diagnosis and clues to misdiagnosis. In: Burks J, Johnson K, eds. Multiple Sclerosis, Medical Management, and Rehabilitation. New York: Demos Medical Publishers; 2000:127-38.

10. Lorenzoni P, Scola R, Kay C, Werneck L. Myasthenia gravis and multiple sclerosis: an uncommon presentation. Arq Neuropsiquiatr. 2008;66(2A):25153.

11. Iwamoto K, Oka H, Utsuki S, Ozawa T, Fujii K. Late-onset multiple sclerosis mimicking brain tumor: a case report. Brain Tumor Pathol. 2004;21(2):83-86.

12. Weinshenker B, Bass B, Rice G, et al. The natural history of multiple sclerosis: a geographically-based study. I. Clinical course and disability. Brain. 1989;112(Pt 1):133-46.

13. National MS Society. What is multiple sclerosis? Available at: http:// www.nationalmssociety.org/about-multiple-sclerosis/what-is-ms/index.aspx. Accessed January 13, 2009.

14. Olek MJ. Epidemiology, risk factors, and clinical features of multiple sclerosis in adults. Available at: http://www.uptodate.com/patients/content/ topic.do?topicKey= rKXvq3fAEQgE2W. Accessed January 8, 2009.

15. Schumacher GA, Beebe G, Kebler RF, et al. Problems of experimental trials of therapy in multiple sclerosis: report by the Panel on the Evaluation of Experimental Trials of Therapy in Multiple Sclerosis. Ann N Y Acad Sci. 1965;122:552-68.

16. Compston A, Coles A. Multiple sclerosis. Lancet. 2002;359(9313):122131.

17. Kurtzke JF. Rating neurologic impairment in multiple sclerosis: an expanded disability status scale (EDSS). Neurology. 1983;33(11):1444-52.

18. All About Multiple Sclerosis. Expanded disability status scale. Available at: http://www.mult-sclerosis.org/expandeddisabilitystatusscale.html. Accessed January 13, 2009.

19. Freedman MS, Thompson EJ, Deisenhammer F, et al. Recommended standard of cerebrospinal fluid analysis in the diagnosis of multiple sclerosis: a consensus statement. Arch Neurol. 2005;62(6):865-70.

20. UpToDate for Patients. Olek MJ. Diagnosis of multiple sclerosis in adults. Available at http://www.uptodate.com/patients/content/topic.do?topicKey= $\sim$ OcYYJoCs3MH3Sc\&selectedTitle=1 149\&source=search_result. Accessed January 13, 2009.

21. McDonald WI, Compston A, Edan G, et al. Recommended diagnostic criteria for multiple sclerosis: guidelines from the International Panel on the diagnosis of multiple sclerosis. Ann Neurol. 2001;50(1):121-27.

22. Polman CH, Reingold SC, Edan G, et al. Diagnostic criteria for multiple sclerosis: 2005 revisions to the "McDonald Criteria." Ann Neurol. 2005;58(6):840-46.

23. Stüve O, Bennett JL, Hemmer B, et al. Pharmacological treatment of early multiple sclerosis. Drugs. 2008;68(1):73-83.

24. Brex PA, Ciccarelli O, O'Riordan JI, Sailer M, Thompson AJ, Miller DH. A longitudinal study of abnormalities on MRI and disability from multiple sclerosis. N Engl J Med. 2002; 346(3):158-64.

25. Frohman EM, Goodin DS, Calabresi PA, et al. The utility of MRI in suspected MS: report of the Therapeutics and Technology Assessment Subcommittee of the American Academy of Neurology. Neurology. 2003; 61(5):602-11.

26. National Clinical Advisory Board of the National Multiple Sclerosis Society (NMSS). Expert opinion paper. Disease management consensus statement, 2007. Available at: http://www.nationalmssociety.org/about-multiple-sclerosis/treatments/download.aspx?id=8. Accessed January 8, 2009.

27. Comi G. Treatment with glatiramer acetate delays conversion to clinically definite multiple sclerosis (CDMS) in patients with clinically isolated syndromes (CIS). Presented at: AAN 60th Annual Meeting; April 12-19, 2008; Chicago, Illinois. LBS.003. 
28. Kappos L, Polman CH, Freedman MS, et al. Treatment with interferon beta-lb delays conversion to clinically definite and McDonald MS in patients with clinically isolated syndromes. Neurology. 2006;67(7):1242-49.

29. Comi G, Filippi M, Barkhof F, et al. Effect of early interferon treatment on conversion to definite multiple sclerosis: a randomised study. Lancet. 2001;357(9268):1576-82.

30. Jacobs LD, Beck RW, Simon JH, et al. Intramuscular interferon beta-la therapy initiated during a first demyelinating event in multiple sclerosis. CHAMPS Study Group. N Engl J Med. 2000;343:898-904.

31. Kinkel RP, Kollman C, O'Connor P, et al. IM interferon beta-la delays definite multiple sclerosis 5 years after a first demyelinating event. Neurology. 2006;66(5):678-84

32. Kappos L, Freedman MS, Polman CH, et al. Effect of early versus delayed interferon beta-lb treatment on disability after a first clinical event suggestive of multiple sclerosis: a 3-year follow-up analysis of the BENEFIT study. Lancet. 2007;370(9585):389-97.

33. Polman $\mathrm{CH}$, O'Connor PW, Havrdova E, et al. A randomized, placebocontrolled trial of natalizumab for relapsing multiple sclerosis. N Engl J Med. 2006;354(9):899-910.

34. O'Connor PW, Goodman A, Kappos L, et al. The efficacy of natalizumab monotherapy over 3 years of treatment in patients with relapsing multiple sclerosis. [Poster abstract P06.082] Presented at: AAN 59th Annual Meeting. Available at: http://www.abstracts2view.com/aan2007boston/view. php?nu=AAN07L_P06.082\&terms=. Accessed January 8, 2009.

35. Hartung HP, Gonsette R, Konig N, et al., for the Mitoxantrone in Multiple Sclerosis Study Group (MIMS). Mitoxantrone in progressive multiple sclerosis: a placebo controlled, double-blind, randomised, multicentre trial. Lancet. 2002;360(9350):2018-25.

36. Durelli L, Verdun E, Barbero P, et al. Every-other-day interferon betalb versus once-weekly interferon beta-la for multiple sclerosis: results of a 2-year prospective randomised multicentre study (INCOMIN). Lancet. 2002;359(9316):1453-60.

37. Panitch H, Goodin DS, Francis G, et al. Randomized, comparative study of interferon beta-la treatment regimens in MS: The EVIDENCE Trial. Neurology. 2002;59(10):1496-506.

38. Clanet M, Radue EW, Kappos L, et al. A randomized, double-blind, dose-comparison study of weekly interferon beta-la in relapsing MS. Neurology 2002;59(10):1507-17.

39. Mikol DD, Barkhof F, Chang P, et al. Comparison of subcutaneous interferon beta-la with glatiramer acetate in patients with relapsing multiple sclerosis (the REbif vs Glatiramer Acetate in Relapsing MS Disease [REGARD] study): a multicentre, randomised, parallel, open-label trial. Lancet Neurol. 2008;7(10):903-14

40. O'Connor P, Arnason B, Comi G, et al. Interferon beta-1b 500mcg, interferon beta-1b $250 \mathrm{mcg}$ and glatiramer acetate: primary outcomes of the betaferon/betaseron efficacy yielding outcomes of a new dose study. Poster abstract presented at: AAN 60th Annual Meeting; April 12-19, 2008; Chicago, Illinois. LBS.004.

41. UpToDate for Patients. Olek MJ. Treatment of relapsing and remitting multiple sclerosis. Available at: http://www.uptodate.com/patients/content/ topic.do?topicKey= N00VdbHPUlMU6_\&selectedTitle=1 142\&source=sear ch_result. Accessed January 8, 2009.

42. U.S. Food and Drug Administration. Copaxone (glatiramer acetate). Available at: http://www.fda.gov/cder/foi/label/2001/20622s15lbl.pdf. Accessed January 13, 2009.

43. U.S. Food and Drug Administration. Highlights of Prescribing Information for Tysabri (natalizumab). Available at: www.fda.gov/cder/foi/ label/2008/125104s033lbl.pdf. Accessed January 8, 2009.
44. Kleinschmidt-DeMasters BK, Tyler KL. Progressive multifocal leukoencephalopathy complicating treatment with natalizumab and interferon beta-la for multiple sclerosis. N Engl J Med. 2005;353(4):369-74. Available at: http://content.nejm.org/cgi/content/abstract/353/4/369. Accessed January 13, 2009.

45. Langer-Gould A, Atlas SW, Green AJ, Bollen AW, Pelletier D. Progressive multifocal leukoencephalopathy in a patient treated with natalizumab. $N$ Engl J Med. 2005;353(4):375-81.

46. Goodin DS, Cohen BA, O'Connor P, Kappos L, Stevens JC. Assessment: the use of natalizumab (Tysabri) for the treatment of multiple sclerosis (an evidence-based review)a; report of the Therapeutics and Technology Assessment Subcommittee of the American Academy of Neurology. Neurology. 2008;71(10):766-73.

47. Novantrone (mitoxantrone for injection concentrate). Prescribing Information. EMD Serono, OSI Pharmaceuticals, Melville, New York, 2008 Available at: http://www.novantrone.com/assets/pdf/novantrone_prescribing_info.pdf. Accessed January 13, 2009.

48. Mohr DC, Goodkin DE, Likosky W, Gatto N, Baumann KA, Rudick RA. Treatment of depression improves adherence to interferon beta-lb therapy for multiple sclerosis. Arch Neurol. 1997;54(5):531-33.

49. Clerico M, Barbero P, Contessa G, Ferrero C, Durelli L. Adherence to interferon-beta treatment and results of therapy switching. J Neurol Sci. 2007;259(1-2):104-08.

50. Rio J, Porcel J, Tellez N, et al. Factors related with treatment adherence to interferon beta and glatiramer acetate therapy in multiple sclerosis. Mult Scler. 2005;11(3):306-09.

51. Fraser C, Hadjimichael O, Vollmer T. Predictors of adherence to Copaxone therapy in individuals with relapsing-remitting multiple sclerosis. J Neurosci Nurs. 2001;33(5):231-39.

52. Fraser C, Morgante L, Hadjimichael O, Vollmer T. A prospective study of adherence to glatiramer acetate in individuals with multiple sclerosis. $J$ Neurosci Nurs. 2004;36(3):120-29.

53. Denis L, Namey M, Costello K, et al. Long-term treatment optimization in individuals with multiple sclerosis using disease-modifying therapies: a nursing approach. J Neurosci Nurs. 2004;36(1):10-22.

54. International Working Group for Treatment Optimization in MS. Treatment optimization in multiple sclerosis: report of an international consensus meeting. Eur J Neurol. 2004;11(1):43-47.

55. National MS Society: Pregnancy and Reproductive Issues. Available at: http://www.nationalmssociety.org/living-with-multiple-sclerosis/healthyliving/pregnancy/index.aspx. Accessed January 13, 2009.

56. University of Virginia Health System: High-risk pregnancy, MS. Available at: http://www.healthsystem.virginia.edu/uvahealth/peds_hrpregnant/neuroms.cfm Accessed January 13, 2009.

57. Bishop B. Women's health issues and neurologic disease. J Nurs Pract. 2006;2(8):544-46.

58. Goodin DS, Frohman EM, Hurwitz B, et al. Neutralizing antibodies to interferon beta: assessment of their clinical and radiographic impact: an evidence report: report of the Therapeutics and Technology Assessment Subcommittee of the American Academy of Neurology. Neurology. 2007;68(13):977-84.

59. Teitelbaum D, Brenner T, Abramsky O, Aharoni R, Sela M, Arnon R. Antibodies to glatiramer acetate do not interfere with its biological functions and therapeutic efficacy. Mult Scler. 2003;9(6):592-99.

60. Sorensen PS, Deisenhammer F, Duda P, et al. Guidelines on use of anti-IFN-beta antibody measurements in multiple sclerosis: report of an EFNS Task Force on IFN-beta antibodies in multiple sclerosis. Eur J Neurol. 2005;12(11):817-27.

61. Ford CC, Johnson KP, Lisak RP, et al. A prospective open-label study of glatiramer acetate: over a decade of continuous use in multiple sclerosis patients. Mult. Scler. 2006;12:309-20. 
62. Kappos L, Traboulsee A, Constantinescu C, et al. Long-term subcutaneous interferon beta-la therapy in patients with relapsing-remitting MS. Neurology. 2006;67:944-53.

63. Ebers G, Traboulsee A, Langdon D, Goodin D, Konieczny A, The Betaseron ${ }^{\circledR} /$ Betaferon ${ }^{\circledR}$ LTF Study Group. The interferon beta-1b 16-year long-term follow-up study: the results. Poster presented at: 58th Annual Meeting of the AAN; April 1-8, 2006; San Diego, California. P 1.079.

64. Fisher E, Rudick RA, Simon JH, et al. Eight-year follow-up study of brain atrophy in patients with MS. Neurology. 2002;59:1412-20.

65. Ford C, Johnson K, Kachuck N, et al. Continuous long-term immunomodulatory therapy in relapsing multiple sclerosis: results from the 15-year analysis of the U.S. Prospective Open-Label Study of Glatiramer Acetate. Presented at: World Congress on Treatment and Research in Multiple Sclerosis; September 18, 2008; Montreal, Canada. P44.

66. Noseworthy JH, Lucchinetti C, Rodriguez M, Weinshenker BG. Multiple sclerosis. N Engl J Med. 2000;343(13):938-52

67. Neema M, Stankiewicz J, Arora A, Guss ZD, Bakshi R. MRI in multiple sclerosis: what's inside the toolbox? Neurotherapeutics. 2007;4(4):602-17.

68. Wolansky LJ, Cook SD, Sheynzon V, et al. Betaseron ${ }^{\circledR}$ vs. Copaxone ${ }^{\circledR}$ in multiple sclerosis with triple-dose gadolinium and 3-T MRI Endpoints (BECOME): efficacy of the optimised MRI protocol and announcement of primary study outcome. Presented at: ECTRIMS 22nd Congress of the European Committee for Treatment and Research in Multiple Sclerosis; September 27-30, 2006; Madrid, Spain. P 365.

69. Wolansky L, Cook S, Skurnick J, et al. Betaseron vs. Copaxone in MS with triple-dose gadolinium and 3-T MRI Endpoint (BECOME): announcement of final primary study outcome. Poster presented at: ECTRIMS 23rd Congress of the European Committee for Treatment and Research in Multiple Sclerosis; October 11-14, 2007; Prague, Czech Republic. P 206.
70. Filippi M, Rovaris M, Rocca MA, Sormani MP, Wolinsky JS, Comi G; European/Canadian Glatiramer Acetate Study Group. Glatiramer acetate reduces the proportion of new MS lesions evolving into "black holes." Neurology. 2001;57(4):731-33.

71. Miller DH, Soon D, Fernando KT, et al. MRI outcomes in a placebo-controlled trial of natalizumab in relapsing MS. Neurology. 2007;68(17):1390401.

72. Bagnato F, Evangelou IE, Gallo A, Gaindh D, Yao K. The effect of interferon-beta on black holes in patients with multiple sclerosis. Expert Opin Biol Ther. 2007;7(7):1079-91.

73. Khan O, Mackenzie M, Bao F, et al. Effect of disease-modifying therapies on brain atrophy in early and mildly affected relapsing-remitting multiple sclerosis over a long-term period: results of a five-year imaging study. Poster presented at: ECTRIMS 23rd Congress; October 11-14, 2007; Prague, Czech Republic. P 603

74. Cohen BA, Khan O, Jeffery DR, et al. Identifying and treating patients with suboptimal responses. Neurology. 2004;63(12 Suppl 6):S33-S40.

75. International Working Group for Treatment Optimization in MS. Treatment optimization in multiple sclerosis: report of an international consensus meeting. Eur J Neurol. 2004;11(1):43-47.

76. Freedman MS, Patry DG, Grand'Maison F, et al. Treatment optimization in multiple sclerosis. Can J Neurol Sci. 2004;31(2):157-68.

77. Zwibel HL, Copolymer-1 Treatment Study Principal Investigators. Glatiramer acetate in treatment-naive and prior interferon-beta-lb-treated multiple sclerosis patients. Acta Neurol Scand. 2006;113(6):378-86.

78. Caon C, Din M, Ching W, Tselis A, Lisak R, Khan O. Clinical course after change of immunomodulating therapy in relapsing-remitting multiple sclerosis. Eur J Neurol. 2006;13(5):471-74.

79. Carra A, Onaha P, Luetic G, et al. Therapeutic outcome 3 years after switching of immunomodulatory therapies in patients with relapsing-remitting multiple sclerosis in Argentina. Eur J Neurol. 2008;15(4):386-93.

\section{Disclaimer}

These materials and all other materials provided in conjunction with continuing medical education activities are intended solely for purposes of supplementing continuing medical education programs for qualified health care professionals. Anyone using the materials assumes full responsibility and all risk for their appropriate use.

Continuing education for this activity is processed through either the AMCP.org Online Learning Center site at www. amcp.org (CE/CME Center) or through PRIME ${ }^{\circledR}$ at www.primeinc.org/jmcp/ms. No mailed forms will be accepted.

The posttest worksheet on the following page is provided to assist you in marking your answers prior to entering the online CE Center for submission.

In order to receive CE credit for this program, you must complete the following forms online:

1. Posttest form for this program, "Review of the Clinical Update Regarding Interventions for Multiple Sclerosis," on the AMCP.org CME/CE Center or through PRIME ${ }^{\circledR}$ at www.primeinc.org/jmcp/ms. To receive credit, you must receive a score of $70 \%$. You will have 2 opportunities to pass the posttest.

\section{Program Evaluation form}

Upon successful completion of this program, you will automatically receive your CE statement. Your CE credits will be automatically archived and tracked for you on the AMCP.org CME/CE Center site or through PRIME ${ }^{\circledR}$ at www.primeinc.org/jmcp/ms. All information is confidential. 


\section{Review of the Clinical Debate Regarding Interventions for Multiple Sclerosis}

$\mathrm{AE}$ Pharmacists

Professional Resources in Management Education, Inc. (PRIME ${ }^{\circledR}$ ) is accredited by the Accreditation Council for Pharmacy Education (ACPE) as a provider of continuing pharmaceutical education. A total of 0.150 CEUs (1.5 contact hours) will be awarded and a continuing education statement will be sent to pharmacists for successful completion of this continuing education program, which is defined as receiving a minimum score of $70 \%$ on the post test and completion of the Program Evaluation form. ACPE Universal Program Number. 255-000-08-028-H01-P.

Release date: February 1, 2009; Expiration date: February 1, 2010.

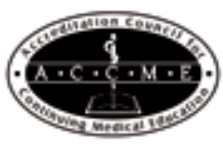

Physicians

Professional Resources in Management Education, Inc. (PRIME $\left.{ }^{\circledR}\right)$ is accredited by the Accreditation Council for Continuing Medical Education (ACCME) to provide continuing medical education for physicians. This activity has been planned and implemented in accordance with the Essential Areas and Policies of ACCME through sponsorship of PRIME $^{\circledR}$. PRIME ${ }^{\circledR}$ designates this educational activity for a maximum of 1.5 category 1 credits toward the AMA Physician's Recognition Award. Each physician should claim only those hours of credit that he/she actually spent on the activity.

Release date: February 1, 2009; Expiration date: February 1, 2010.

Continuing education for this program ("Review of the Clinical Update Regarding Interventions for Multiple Sclerosis") is processed through either AMCP at www.amcp.org (CME/CE Center) or through PRIME ${ }^{\circledR}$ at www.primeinc.org/jmcp/ms. Participants who attended the satellite symposium, "Resolving the Clinical Debate Regarding Interventions in Multiple Sclerosis," held at the AMCP annual meeting and who obtained continuing education credit for that learning activity held on October 15, 2008, are not eligible for continuing education credit for this supplement.

The posttest worksheet is provided to assist you in marking your answers prior to entering the online CE center for submission; these pages cannot be submitted for CE credits.

\section{Posttest Worksheet: Review of the Clinical Debate Regarding Interventions for Multiple Sclerosis}

1. Which of the following is NOT true about multiple sclerosis (MS)?
a. MS is an inflammatory demyelinating disorder of the central nervous system.
b. MS is believed to have an autoimmune etiology.
c. MS is a highly treatable disease that usually goes into full remission.
d. MS is a chronic, neurologic degenerative condition that lasts an individual's lifetime.

2. What would you NOT prescribe initially to a patient who is diagnosed with relapsing-remitting MS?
a. Corticosteroids
b. Rituximab
c. Interferon beta products
d. Glatiramer acetate

3. Which of the following is NOT true regarding MS?
a. MS is the most common neurologic disorder in young adults.
b. One of the characteristics of MS is axonal degeneration.
c. The prevalence of MS is roughly equivalent in females and males.
d. MS is more prevalent among Caucasians.

4. All of the following have been identified as medication adherence challenges in caring for patients with MS EXCEPT:
a. Managing comorbidities
b. Perceived lack of efficacy of DMTs
c. Needle phobia
d. Inconsistent coverage for DMTs from health plan to health plan

5. Which type of MS are the majority of patients diagnosed with?
a. Relapsing-remitting MS
b. Secondary-progressive MS
c. Primary-progressive MS
d. Benign MS

To complete this activity, go to www.amcp.org (CE/CME

Center) or www.primeinc.org/jmcp/ms, where you will access the posttest and evaluation form. 
6. An MS patient has been injecting herself with a DMT and does well until 2 months after starting therapy. She experiences right leg weakness and total numbness of her left foot. She also complains of fever, nausea, and muscle pain, as well as redness, swelling, and injection site pain. The following day, she calls her neurologist to tell her about these symptoms. Which of the following would be the best treatment strategy for this patient at this time?

a. Continue the DMT at the present dose

b. Discontinue the DMT

c. Continue the DMT but decrease the dose by half

d. Immediately change DMT agents

7. Which of the following would be the best strategy to use in enhancing adherence to therapy in patients with MS?

a. Make a specific plan with the patient to address problems when they occur

b. Provide broad-based education on MS

c. Keep communication channels open, especially when beginning therapy

d. All of the above

8. Which of the following statements best describes the psychological impact of MS?

a. The prevalence of clinical depression in patients with MS does not affect disease progression.

b. Depressed MS patients typically display decreased adherence to therapy.

c. Gender is a predictor of emotional disturbances in MS patients.

d. Treatment of comorbid depression does not impact MS therapy adherence in patients.

9. During which circumstance(s) should you prescribe natalizumab to treat multiple sclerosis?

a. When a patient has had an inadequate response to first-line DMT

b. When a patient is unable to tolerate treatment with first-line DMT

c. For the management of exacerbations

d. Both A and B

10. Which statement best describes pregnancy strategies in MS?

a. There is no evidence that pregnancy in MS impairs fertility or leads to congenital malformations.

b. Low-dose IFN $\beta$-la is approved for use during pregnancy.

c. Pregnancy may affect the long-term course of MS.

d. Women with MS should not become pregnant because symptoms may worsen and spontaneous abortion may occur.
11. Which DMT has the most favorable pregnancy rating (Category B)?

a. Mitoxantrone

b. IFN $\beta-1 \mathrm{a}$

c. Glatiramer acetate

d. Natalizumab

12. Which statement is true regarding neutralizing antibodies in patients receiving therapy for MS?

a. Both interferon beta (IFN $\beta$ ) formulations and natalizumab may elicit development of neutralizing antibodies

b. Neutralizing antibodies may limit the effectiveness of therapy for MS as measured by MRI activity.

c. The presence of neutralizing antibodies may be transient.

d. All of these statements are true.

13. How long should DMT be used in patients with MS?

a. Patients should receive treatment until they do not have a relapse for 6 months, after which therapy should be stopped until the next flare or relapse.

b. Patients should receive treatment for up to 10 years depending on the drug because long-term data has not gone beyond this time-frame.

c. Patients should receive treatment indefinitely unless they cannot tolerate it or it has no benefit.

d. Patients should receive treatment indefinitely even if they have no benefit or have tolerability issues.

14. A suboptimal response to therapy for MS can be defined as:

a. Lack of significant reduction in relapse rate compared to pretreatment relapse rate

b. Progression of physical disability, cognitive dysfunction, or increasing difficulty with activities of daily living (ADLs)

c. Increasing changes on MRI scan

d. All of the above

15. Which of the following agents used for treating MS has been linked to cases of PML (progressive multifocal leukoencephalopathy)?
a. IFN $\beta$ agents
b. Glatiramer acetate
c. Natalizumab
d. Mitoxantrone

To complete this activity, go to www.amcp.org (CE/CME Center) or www.primeinc.org/jmcp/ms, where you will access the posttest and evaluation form. 


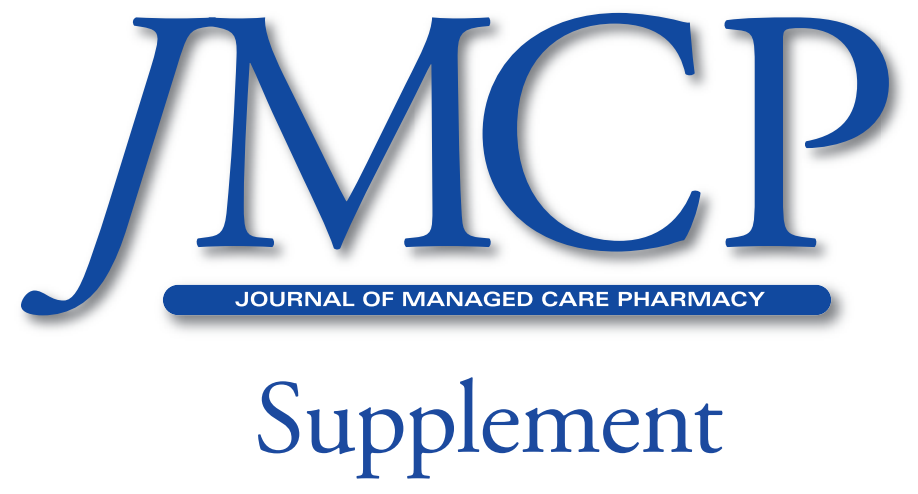

